\title{
A real-world study of effectiveness of intravitreal bevacizumab and ranibizumab injection for treating retinal diseases in Thailand
}

Suthasinee Kumluang ${ }^{1}$, Lily Ingsrisawang ${ }^{2^{*}}$ (D), Sermsiri Sangroongruangsri ${ }^{1,3}$, Usa Chaikledkaew ${ }^{1,3}$, Tanapat Ratanapakorn ${ }^{4}$, Paisan Ruamviboonsuk ${ }^{5}$, Wongsiri Taweebanjongsin ${ }^{6}$, Janejit Choovuthayakorn ${ }^{7}$, Somanus Thoongsuwann ${ }^{8}$, Prut Hanutsaha ${ }^{9}$, Kittisak Kulvichit ${ }^{10}$, Thitiporn Ratanapojnard ${ }^{11}$, Warapat Wongsawad ${ }^{6}$, Pattara Leelahavarong ${ }^{1}$ and Yot Teerawattananon ${ }^{1}$

\begin{abstract}
Background: To evaluate the effectiveness of intravitreal bevacizumab (IVB) and intravitreal ranibizumab (IVR) in actual practice for treating patients with retinal diseases in Thailand.

Methods: A prospective, multi-centre, observational study was conducted among eight hospitals in their ophthalmology outpatient departments. Participants consisted of patients who had previously not received any IVB or IVR treatment between 2013 and 2014. The primary outcome measurement was the change in best-corrected visual acuity (BCVA) at the end of the follow-up period compared to baseline.

Results: There were 1629 treatment-naïve patients for the pro re nata (PRN) treatment pattern and 226 treatmentnaive patients for the three-injections (3lnj) treatment pattern. BCVA improvements were found in 35\% of the PRN group and $47 \%$ of the 3 Inj group; however, it was not clinically meaningful between the IVB and IVR groups ( $P$-value $=0$. 568 for PRN, P-value $=0.103$ for 3lnj). A multivariable logistic regression (using the propensity score) showed that positive factors associated with vision improvement for the PRN pattern were the number of drug injections, having retinal vein occlusion, and under 60 years of age, while good BCVA at baseline was a negative predictive factor. For the 3Inj pattern, under 60 years of age and baseline BCVA were statistically significant predictors. Nonetheless, diabetes mellitus (DM) without other comorbidities was a statistically significant predictor of low response to vision improvement compared to DM with other comorbidities.

Conclusions: This study was the first observational, prospective study to evaluate the real-life effectiveness of IVB and IVR in Thailand. The majority of participants who used IVB or IVR showed improvements in BCVA after treatment. Further evaluation such as long-term follow-ups and subsequent comparison of effectiveness between IVB and IVR should be investigated due to the limited sample of IVR patients.
\end{abstract}

Trial registration: Thai Clinical Trial Registry TCTR20141002001. Registered 02 October 2014 (retrospectively registered).

Keywords: Bevacizumab, Ranibizumab, Retinal diseases, Real world, Vision improvement

\footnotetext{
* Correspondence: fscilli@ku.ac.th; fscilli.ing@gmail.com

${ }^{2}$ Department of Statistics, Faculty of Science, Kasetsart University, Bangkok,

Thailand

Full list of author information is available at the end of the article
}

(c) The Author(s). 2019 Open Access This article is distributed under the terms of the Creative Commons Attribution 4.0 International License (http://creativecommons.org/licenses/by/4.0/), which permits unrestricted use, distribution, and reproduction in any medium, provided you give appropriate credit to the original author(s) and the source, provide a link to the Creative Commons license, and indicate if changes were made. The Creative Commons Public Domain Dedication waiver (http://creativecommons.org/publicdomain/zero/1.0/) applies to the data made available in this article, unless otherwise stated. 


\section{Background}

Neovascular age-related macular degeneration (nAMD), diabetic macular edema (DME), and retinal vein occlusion (RVO) are well-recognised as the most common causes of visual impairment and blindness in elderly populations [1-4]. Population-based studies have highlighted the global prevalence of these diseases, with the pooled prevalence of AMD and late AMD at 8.69 and 0.37\%, respectively [5], DME prevalence at $7 \%[2,6,7]$, and ageand sex-standardised RVO prevalence at $0.5 \%$.

These retinal diseases are also major eye problems in Thailand. The nAMD epidemiological cross-sectional survey in 2010 revealed that the prevalence rate of AMD among the Thai population over 50 years of age was $12.2 \% ; 0.7 \%$ of that figure was nAMD [8]. The prevalence of RVO was reported to be between 0.5 and $2 \%$ of the total population [1], and DME prevalence was found to be between 2 and 3\% in Thai diabetic patients [2, 9].

Vascular endothelial growth factor (VEGF) plays a critical role in vision loss due to angiogenesis and vascular hyperpermeability. Anti-VEGF drugs such as bevacizumab (off-label) and ranibizumab (licensed) have been widely used by ophthalmologists for treating nAMD, DME, and RVO since 2006 [10, 11]. Although numerous studies have shown that both drugs are beneficial and comparatively effective for these retinal diseases [12, 13], price differences between the two medications have driven the use of off-label intravitreal bevacizumab (IVB) as a less expensive alternative, with many countries experiencing good evidence-based results [14-16].

In 2012, a systematic review and meta-analysis conducted by the Health Intervention and Technology Assessment Program (HITAP) [9] indicated that IVB was superior to non-pharmaceutical interventions in nAMD and DME. The results also found that clinical outcomes such as improving Visual Acuity (VA), reducing Central Macular Thickness (CMT), and treatment responses between IVB and intravitreal ranibizumab (IVR) were indifferent for both diseases. Finally, after reporting the results to the Sub-committee for the Development of the National List of Essential Medicines (NLEM) of Thailand, the Sub-committee approved the inclusion of bevacizumab into the NLEM for NAMD and DME despite its off-label status to address the issues of anti-VEGF drug affordability and IVB treatment accessibility. This was because the three major public health insurance schemes (HIS) in Thailand - which reference the NLEM as the basic package for drug benefits covers the majority of the Thai population; the Civil Servant Medical Benefit Scheme (CSMBS) covers 9\%, the Social Security Scheme (SSS) covers 16\%, and the Universal Coverage Scheme (UCS) covers 75\% [17-19]. However, certain drugs on the non-essential drug (NED) lists - including ranibizumab - can only be reimbursed by those under the CSMBS while the other two schemes require out-of-pocket payments. For this reason, not only does it contribute to differences in services provided but it also results in inequitable access to essential medicines - contradicting the notion that access to essential health interventions is considered a basic right for patients.

The purpose of this study is to analyse the clinical outcomes of IVB and IVR for treating retinal diseases using real-world data in Thailand. The evidence generated from this study will provide information on whether IVB should be used in macular diseases. It is also expected that the results of this study will be used to inform the NLEM Sub-committee about further optimisations, as well as to provide a reference for decision-makers in other developing countries with similar interests.

\section{Methods}

\section{Participant and study design}

This study was part of a main study which focuses on the safety of bevacizumab in real-world settings. The parent study was an observational, non-interventional, multi-centre, prospective study and was conducted in 8 Thai tertiary and teaching hospitals between January 2013 and August 2014 [20]. In both this study and the parent study, participants underwent comprehensive ophthalmologic examinations and treatments based on normal clinical practices. Treatment plans or decisions were left to the clinical and discretionary judgment of the treating retina specialist over the follow-up period.

Inclusion criteria for this study included retinal disease patients who had not been previously treated with either IVB $(1.25 \mathrm{mg} / 0.05 \mathrm{ml})$ or IVR $(0.5 \mathrm{mg} / 0.05 \mathrm{ml})$, were over 18 years old, and did not switch between IVB and IVR upon receiving treatment during the study period (6 months). Exclusion criteria consisted of any history with previous IVB or IVR injections and switching of treatment to something other than an intravitreal VEGF inhibitor. Prior to data collection, informed written consent was obtained from each patient.

\section{Interventions}

This study followed routine clinical practice. Decisions about eligibility and anti-VEGF drug selection $(1.25 \mathrm{mg}$ of IVB or $0.5 \mathrm{mg}$ of IVR) were based on the clinical and discretionary judgment of the ophthalmologists, and these decisions were aligned with the retinal treatment guideline [21] and current NLEM treatment guidelines for the usage and monitoring of bevacizumab for nAMD and DME patients [22, 23]; they were also consistent with the two previous landmark RCTs [24, 25].

In this study, the interventions of interest were classified into two groups: 1) an initial treatment course called the three-injections pattern (3Inj) - also known as the 
standard regimen - which served as the loading phase of three consecutive intravitreal (IVB or IVR) monthly injections as recommended in the NLEM's criteria [22], and 2) IVB or IVR injections as needed (pro re nata or PRN). These groups were specifically chosen to determine the differences in IVB and IVR for both the NLEM recommendation (the 3Inj pattern) and actual clinical practices (the PRN pattern). To determine VA improvement, BCVA was initially measured prior to any injections to serve as a baseline, and subsequent BCVA measurements in both groups were conducted within 28-35 days after each injection using identical measurement methods [22]. Therefore, BCVA was measured a total of 4 times for the 3Inj group (the 4th BCVA measurement occurred within 35 days after the 3rd injection). However, there was no fixed amount of BCVA measurements for the PRN group as the number of injections depended on the ophthalmologist's prescription.

In terms of classifying patients into the two treatment groups, patients who were prescribed the 3Inj treatment course were considered 3Inj samples. However, to be classified into the PRN treatment group, DME patients needed to have a minimum of 1 anti-VEGF injection but not more than 6 injections per year and nAMD patients needed to have a minimum of 1 anti-VEGF injection but not more than 12 injections per year [22]. Moreover, the NLEM recommends that patients who receive more than 3 injections should automatically be classified into the PRN treatment. For example, if the patient received 6 injections in total, he/she would be considered a sample in both 3Inj and PRN groups. The difference is that the number of injections used for the effective analysis in the 3Inj group would be 3, while the number of injections would be 6 for the PRN pattern group. The reason for this is that the authors would like to know the effectiveness of the drug in its loading phase (3 injections) as well as its effectiveness in actual practice. Subsequently, a data analysis was performed one at a time for each treatment pattern group.

\section{Data collection}

The data collection process comprised patient interviews and medical record reviews. Data quality was carefully managed by training the research staff to interview patients, review medical records, and extract patient data in the designed paper case report forms (pCRFs). Retinal specialists were responsible for verifying the medical data as well as the pCRFs. Once the data were documented in the pCRFs by the first research staff, the pCRFs were randomly reviewed and corrected by the second research staff to ensure accuracy and completeness. Afterwards, an independent double data entry and validation process for the pCRFs was conducted using the Epidata ${ }^{\circ}$ programme. Prior to analysis, the data discrepancy in the database was verified and reconciled - especially the baseline data of participants and the diagnosis or other clinical data - and then compared to the original pCRFs or medical records. If necessary, a third party, such as a retina specialist, was used to confirm the accuracy of the data.

The collected data consisted of demographic and baseline characteristics and information from reviewed medical records for treatments such as ophthalmologic diagnoses, retinal examinations, VA scores, and anti-VEGF drug used. Demographic and baseline characteristics were recorded during the initial visit comprised age, sex, comorbid conditions, and type of health insurance. These characteristics were updated in follow-up visits, and these were scheduled within 35 days of the current visit; the overall duration for tracking follow-up sessions was 6 months.

\section{Outcome measures}

To measure visual function, VA or BCVA was measured on the eye to be treated according to the method used in routine care - by using a patient's eyeglasses or a pinhole. If both eyes were equally qualified, one eye would be chosen at random. The measurement methods comprised four steps from least severe to most severe (5 levels of severity) as follows: 1) Check whether the patient can read a chart. If yes, then use either the Snellen or ETDRS chart depending on the provider's current practice. Otherwise, apply the counting fingers (CF) method; 2) If the patient is unable to count fingers, then apply the hand movements (HM) method; 3 ) If the patient is unable to see hand movements, then apply the perception of light (PL) method; 4) Ask the patient whether he/she can detect light. If yes, then the patient is classified as able to perceive light. Otherwise, he/she is classified as no perception of light (NPL).

Medical data of every patient visit were extracted from medical records. However, CMT measurements were not included as they are optional in Thailand. Due to this reason, the effectiveness analysis included only datasets of patients who had at least one intravitreal anti-VEGF injection and a post-baseline VA assessment on the treated eye; the post-baseline VA assessment must have been measured within 35 days after the previous visit using the same measurement method. For example, if a patient was tested using the pinhole method for their baseline measurement, he/she must be measured by the pinhole method for all subsequent visits until the end of the follow-up period (Fig. 1).

The primary outcome was the proportion of patients who had VA gains of more than two lines (approximately 10 ETDRS letters) at the end of the follow-up period (6 months) compared to the baseline; the secondary outcome was the associated factors that contributed to visual improvement. For the primary outcome, a 


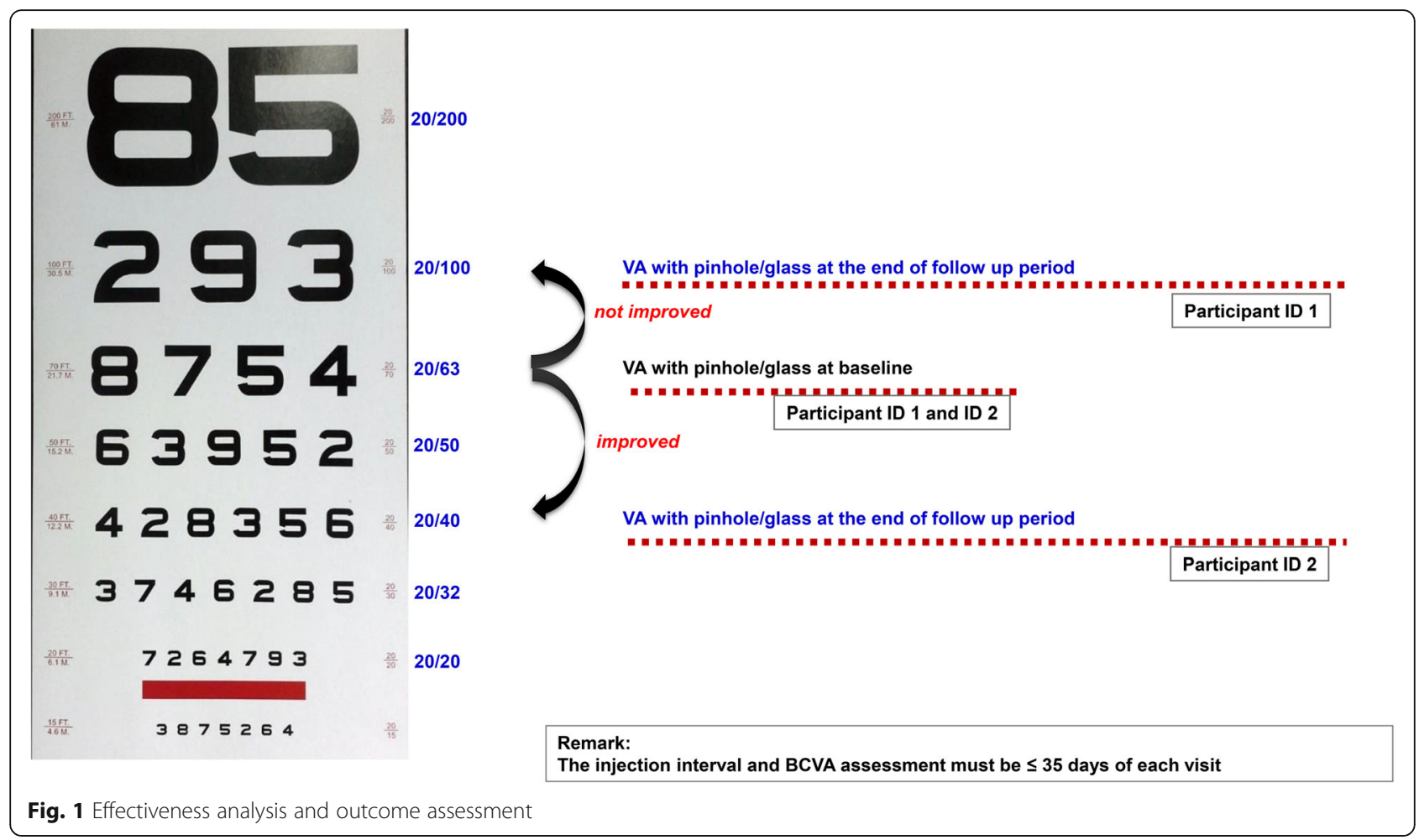

novel method proposed by Gregori et al. [26] was used to convert VA measured by the Snellen chart into approximate EDTRS letter scores in order to simplify the statistical analysis. The equation used is as the following equation:

Approximate ETDRS letters $=85+50 \times \log \quad$ (Snellen fraction).

In terms of outcomes, this study differed from previous clinical trials or retrospective studies such as the Comparison of Age-related macular degeneration Treatments Trials (CATT) and the Inhibition of VEGF in Age-related choroidal Neovascularisation (IVAN) trials. The difference was that those studies included only participants who could read the eye chart. However, in the Thai context, anti-VEGF drugs were prescribed even though patients failed to read the eye chart. If VA was at least two Snellen/ETDRS lines better compared to the baseline or previous visit, it was acceptable in practice as a stable or good clinical response. Additionally, this study assumed that patients who could not read the eye chart showed VA improvement if their VA measurement classification decreased in terms of severity, e.g. VA improved if the baseline VA was measured using PL and the VA method used at the 6-month follow-up was HM.

\section{Statistical analysis}

Demographic characteristics and changes in BCVA and CMT at the baseline and last visit at the end of follow-up period were described in terms of frequencies, percentages, means and standard deviations (SD) or median and interquartile range (IQR). The Mann-Whitney $\mathrm{U}$ test or the Wilcoxon signed-rank test was performed for non-normally distributed variables. A dependent $\mathrm{t}$-test for normally distributed variables was used for continuous variables including the change in VA between the baseline and the end of follow-up period. Frequencies, percentages, the Chi-Square test or Fisher's exact test were used for categorical variables. Univariate and multivariable logistic regression analyses with the propensity score weighting-adjusted method were applied when evaluating the effect of potential variables on vision improvement in order to reduce the effects of selection bias and confounding [27, 28]. A two-sided probability value $(P$-value $)<0.05$ was considered statistically significant. The analyses were performed using Stata12 (StataCorp LP.: Stata Statistical Software: Release 12, College Station, TX, USA).

\section{Results}

\section{Characteristics of the participants}

Among the 3257 anti-VEGF-naive patients included in the effectiveness cohort, 3097 patients received IVB injections (95\%) and 160 patients received IVR injections (5\%). The majority of patients in the IVB group was female while the majority of patients in the IVR group was male. The median age for the IVB group was 57 years (IQR 15, 50-65) and it was 63 years (IQR 19, 54-73) for the IVR group. In terms of the Thai health care schemes, more than $75 \%$ of the IVB 
group were covered under the UCS and SSS whereas only $14 \%$ of the IVB group were covered under the CSMBS. In contrast, nearly $38 \%$ of the IVR group were covered under the CSMBS while the percentage of non-CSMBS patients including those under the UCS and SSS - decreased to $42 \%$. The top three comorbidities for both groups of participants were diabetes mellitus (DM), hypertension (HTN), and dyslipidaemia (DLP). The most common diagnosis in the IVB group was DME while nAMD and polypoidal choroidal vasculopathy (PCV) were the most common diagnoses in the IVR group. Median BCVA at the baseline was approximately 50 letters (IQR $30.10,35-65.10$ ) or $20 / 100$ for the IVB group and 55 letters (IQR 30.10, 35-65.10) or 20/80 for the IVR group. Therefore, baseline visual function was similar between the two groups. Baseline characteristics for all participants are shown in Table 1 .

\section{VA outcomes}

To conduct the effectiveness analysis, only one eye was tested per patient. For those who were treated for both eyes, one eye was randomly selected to be included in the analysis. In total, there were 1629 PRN patients and 226 3Inj patients that used the same VA measurement for all visits during the follow-up period. Out of the 1629 patients who underwent the PRN treatment pattern, 1542 patients (95\%) were from the IVB group and 87 patients (5\%) were from the IVR group.

In terms of changes in VA, only 567 (35\%) patients attained visual improvement equal to or more than 10 ETDRS letters; 535 of these patients (35\%) were from the IVB group and 32 from the IVR group (37\%). Moreover, the 226 3Inj patients - comprising 201 IVB group patients and 25 IVR group patients - were also classified as a subset of the PRN pattern based on the NLEM guidelines described earlier. The change in VA outcomes showed that there were only 107 patients (47\%) - comprising 99 IVB patients (49\%) and 8 IVR patients (32\%) - who showed visual improvement equal to or more than 10 ETDRS letters. The findings from both patterns revealed that vision improvement was not statistically significant different between the IVB and IVR groups (PRN pattern: $p=0.568$ and 3Inj pattern: $p=0.103$ ).

\section{Change in VA letters between baseline and the last follow-up period during the 6-month study period (baseline/3Inj and baseline/PRN)}

Patients who showed VA improvement at the end of the 6-month period for each drug were classified into five groups based on letter count at the baseline. VA scores were classified into ranges as follows: 1) VA score of 6885 letters; 2) VA score of 53-67 letters; 3) VA score of 38-52 letters; 4) VA score of 23-37 letters; and 5) VA score of $0-22$ letters. A significant improvement in ETDRS letters was detected among all patients (Table 2). Improvement in the median ETDRS letters was seen in the PRN group for both IVB and IVR patients; the lone exception where improvement was not seen was for IVR patients who recorded more than 53 ETDRS letters at the baseline. In the follow-up period for the 3Inj pattern, there was a significant improvement in patients who had lower than 67 ETDRS letters in the IVB group but no significant difference in VA scores in the entire IVR group.

\section{Diagnosis and treatment}

Diagnosis of retinal diseases in the study eye is summarized in Table 3. Among the patients who received IVB, the highest percentage of patients consisted of RVO patients in both the PRN (57\%) and 3Inj (63\%) groups. Compared to the proportion of RVO patients, the proportion of patients diagnosed with nAMD and PCV and those diagnosed with DME showed low VA improvement. For the PRN group, there was a $36 \%$ improvement in nAMD and PCV patients and 31\% improvement in DME patients, while the 3Inj group recorded a 46\% improvement for both nAMD and PCV patients and DME patients.

For patients treated with IVR, RVO patients comprised the highest percentage in the PRN group, same as the IVB patients. Out of the 25 IVR patients who were part of the 3Inj group, 8 showed VA improvement (32\%), and 4 of the 12 patients diagnosed with nAMD and PCV showed VA improvement as well. Therefore, the findings showed that both drugs were able to noticeably improve visual function in RVO patients $(57 \%$ in IVB and $46 \%$ in IVR) in the PRN group.

\section{Number of injections}

According to the effectiveness results for the PRN group, most patients received a single injection and measured VA measurement during the follow-up period of not more than 35 days from the injection date $71 \%$ of IVB patients and $57 \%$ of IVR patients - Fig. 2). As shown, the percentage of vision improvement for IVB patients increased noticeably among those who were treated with one to three injections.

The results also showed that based on the retinal diseases and the number of patients who experienced VA improvement, RVO patients represented the highest proportion of those with improved VA at approximately 57 and $46 \%$ for the IVB and IVR groups, respectively, when classified by the total number of intravitreal injections per patient in the PRN pattern (Fig. 3).

\section{Logistic regression}

Table 4 presents the univariate and propensity score-adjusted multivariable analyses for the association of potential factors affecting VA improvement from baseline and at the end of follow-up period for both PRN and 3Inj groups. In the univariate analysis 
Table 1 Baseline characteristics of patients

\begin{tabular}{|c|c|c|c|}
\hline \multirow[t]{2}{*}{ Variables } & \multirow{2}{*}{$\begin{array}{l}\text { IVB }(n=3097) \\
\mathrm{n}(\%)\end{array}$} & \multirow{2}{*}{$\begin{array}{l}\text { IVR }(n=160) \\
\text { n (\%) }\end{array}$} & \multirow[t]{2}{*}{$P$-value } \\
\hline & & & \\
\hline Gender & & & $0.008^{*}$ \\
\hline Female & $1670(54)$ & $69(43)$ & \\
\hline Male & $1427(46)$ & $91(57)$ & \\
\hline Age & & & $0.000^{*}$ \\
\hline Median (IQR; range) & $57(15 ; 50-65)$ & $63(19 ; 54-73)$ & \\
\hline $18-50$ years & $847(27)$ & $33(20)$ & \\
\hline $51-60$ years & $1037(34)$ & $30(19)$ & \\
\hline$>60$ years & $1200(39)$ & $97(61)$ & \\
\hline Universal health coverage & & & $0.000^{*}$ \\
\hline CSMBS & $432(14)$ & $60(38)$ & \\
\hline Non-CSMBS ${ }^{\mathrm{a}}$ & $2358(76)$ & $67(42)$ & \\
\hline Smoking history & & & 0.500 \\
\hline No & $2796(90)$ & $142(89)$ & \\
\hline Yes & $298(10)$ & $18(11)$ & \\
\hline \multicolumn{4}{|l|}{ Underlying Diseases } \\
\hline Diabetes mellitus & $2177(70)$ & $74(46)$ & $0.000^{*}$ \\
\hline Hypertension & $2047(66)$ & $99(62)$ & 0.262 \\
\hline Dyslipidaemia & $1618(52)$ & $84(53)$ & 0.960 \\
\hline Chronic kidney disease & $362(12)$ & $12(8)$ & 0.104 \\
\hline Ischaemic heart disease & $185(6)$ & $10(6)$ & 0.889 \\
\hline Stroke & $120(4)$ & $15(9)$ & $0.001^{*}$ \\
\hline Treated eye & & & $0.001^{*}$ \\
\hline One eye (right or left eye) & $2537(82)$ & $148(92)$ & \\
\hline Both eyes & $560(18)$ & $12(8)$ & \\
\hline Retinal disease $^{b}$ & & & $0.000^{*}$ \\
\hline nAMD and PCV & $452(12)$ & $52(30)$ & \\
\hline Diabetic macular edema (DME) & $1293(35)$ & $21(12)$ & \\
\hline Retinal vein occlusion (RVO) & $461(13)$ & $47(27)$ & \\
\hline Proliferative diabetic retinopathy (PDR) & $963(26)$ & $26(15)$ & \\
\hline Others $^{c}$ & $484(13)$ & $25(15)$ & \\
\hline $\begin{array}{l}\text { Visual Acuity (VA) at baseline }{ }^{\mathrm{b}} \\
\text { (approximate Snellen equivalent) }\end{array}$ & & & 0.195 \\
\hline Reading from Snellen/ETDRS chart & $2427(66)$ & $105(61)$ & \\
\hline $\begin{array}{l}\text { Median VA } \\
\text { (IQR; range) }\end{array}$ & $\begin{array}{l}50.05(20 / 100) \\
(30.10,35-65.10)\end{array}$ & $\begin{array}{l}54.90(20 / 80) \\
(30.10,35-65.10)\end{array}$ & 0.6474 \\
\hline $\mathrm{CF}, \mathrm{HM}, \mathrm{PL}$, and $\mathrm{NPL}$ & $1179(32)$ & $63(37)$ & \\
\hline
\end{tabular}

ancludes Universal Coverage Scheme (UCS) and Social Security Scheme (SSS)

${ }^{\mathrm{b}}$ From the treated eye at baseline (unit: eye)

${ }^{c}$ Other disorders such as vitreous haemorrhage, subretinal haemorrhage, and subretinal fluid

*P-value $<0.05$

CF Counting fingersm, CSMBS Civil Servant Medical Benefit Scheme, ETDRS Early Treatment Diabetic Retinopathy Study, HM Hand movements, IQR interquartile range, $n A M D$ Neovascular age-related macular degeneration, NPL No perception of light, $n$ Number of patients, $P C V$ Polypoidal choroidal vasculopathy, $P L$ Perception of light

of the PRN group, non - DM with and without other comorbidities, disease diagnosis, baseline VA score, and number of drug injections were significantly associated with vision improvement (VA gain $\geq 10$ ETDRS letters at the end of follow-up period compared to baseline VA). However, in the 3Inj pattern, it 
Table 2 Median ETDRS letters for the PRN pattern and 3Inj pattern

\begin{tabular}{|c|c|c|c|c|c|c|c|c|}
\hline \multirow{2}{*}{$\begin{array}{l}\text { ETDRS } \\
\text { letters }\end{array}$} & \multicolumn{2}{|l|}{ IVB } & \multirow[t]{2}{*}{$\mathrm{n}$} & \multirow[t]{2}{*}{$P$-value } & \multicolumn{2}{|l|}{$\underline{\text { IVR }}$} & \multirow[t]{2}{*}{$\mathrm{n}$} & \multirow[t]{2}{*}{$P$-value } \\
\hline & $\begin{array}{l}\text { Median baseline VA } \\
\text { (IQR) }\end{array}$ & $\begin{array}{l}\text { Median VA at } 6 \text { months } \\
\text { (IQR) }\end{array}$ & & & $\begin{array}{l}\text { Median baseline VA } \\
\text { (IQR) }\end{array}$ & $\begin{array}{l}\text { Median VA at } 6 \text { months } \\
\text { (IQR) }\end{array}$ & & \\
\hline \multicolumn{9}{|c|}{ The PRN pattern } \\
\hline 68-85 letters & $\begin{array}{l}69.95 \\
(69.95-76.20)\end{array}$ & $\begin{array}{l}85.00 \\
(80.15-85.00)\end{array}$ & 13 & $0.0013^{*}$ & $\begin{array}{l}69.95 \\
(69.95-69.95)\end{array}$ & $\begin{array}{l}85.00 \\
(85.00-85.00)\end{array}$ & 1 & $* *$ \\
\hline 53-67 letters & $\begin{array}{l}57.80 \\
(54.90-61.14)\end{array}$ & $\begin{array}{l}69.95 \\
(69.95-76.20)\end{array}$ & 84 & $0.0000^{*}$ & $\begin{array}{l}56.35 \\
(54.90-58.88)\end{array}$ & $\begin{array}{l}69.95 \\
(67.52-69.95)\end{array}$ & 4 & 0.0679 \\
\hline 38-52 letters & $\begin{array}{l}46.09 \\
(41.25-50.05)\end{array}$ & $\begin{array}{l}60.08 \\
(54.90-65.10)\end{array}$ & 98 & $0.0000^{*}$ & $\begin{array}{l}46.09 \\
(43.67-50.05)\end{array}$ & $\begin{array}{l}62.54 \\
(57.80-69.95)\end{array}$ & 8 & $0.0116^{*}$ \\
\hline 23-37 letters & $\begin{array}{l}35.00 \\
(35.00-35.00)\end{array}$ & $\begin{array}{l}54.90 \\
(50.15-65.10)\end{array}$ & 99 & $0.0000^{*}$ & $\begin{array}{l}35.00 \\
(29.87-35.00)\end{array}$ & $\begin{array}{l}54.90 \\
(50.05-65.10)\end{array}$ & 6 & $0.0277^{*}$ \\
\hline 0-22 letters & $\begin{array}{l}0.00 \\
(0.00-0.00)\end{array}$ & $\begin{array}{l}35.00 \\
(19.95-54.90)\end{array}$ & 241 & $0.0000^{*}$ & $\begin{array}{l}0.00 \\
(0.00-4.90)\end{array}$ & $\begin{array}{l}57.80 \\
(57.80-59.97)\end{array}$ & 13 & $0.0016^{*}$ \\
\hline \multicolumn{9}{|c|}{ The 3Inj pattern } \\
\hline 68-85 letters & $\begin{array}{l}76.20 \\
(69.95-76.20)\end{array}$ & $\begin{array}{l}85.00 \\
(85.00-85.00)\end{array}$ & 3 & 0.1025 & $\begin{array}{l}69.95 \\
(69.95-69.95)\end{array}$ & $\begin{array}{l}85.00 \\
(85.00-85.00)\end{array}$ & 1 & $* *$ \\
\hline 53-67 letters & $\begin{array}{l}60.08 \\
(54.90-61.14)\end{array}$ & $\begin{array}{l}69.95 \\
(69.95-80.15)\end{array}$ & 15 & $0.0006^{*}$ & $\begin{array}{l}59.97 \\
(59.97-59.97)\end{array}$ & $\begin{array}{l}69.95 \\
(69.95-69.95)\end{array}$ & 1 & $* *$ \\
\hline 38-52 letters & $\begin{array}{l}46.09 \\
(45.21-50.05)\end{array}$ & $\begin{array}{l}65.10 \\
(60.08-69.95)\end{array}$ & 22 & $0.0000^{*}$ & $\begin{array}{l}46.09 \\
(46.09-46.09)\end{array}$ & $\begin{array}{l}65.10 \\
(65.10-65.10)\end{array}$ & 1 & $* *$ \\
\hline 23-37 letters & $\begin{array}{l}35.00 \\
(35.00-35.00)\end{array}$ & $\begin{array}{l}60.03 \\
(54.90-69.95))\end{array}$ & 37 & $0.0000^{*}$ & $\begin{array}{l}32.43 \\
(29.87-35.00)\end{array}$ & $\begin{array}{l}67.53 \\
(65.10-69.95)\end{array}$ & 2 & 0.1797 \\
\hline 0-22 letters & $\begin{array}{l}0.00 \\
(0.00-0.00)\end{array}$ & $\begin{array}{l}50.05 \\
(35.00-57.80)\end{array}$ & 1 & $* *$ & $\begin{array}{l}0.00 \\
(0.00-0.00)\end{array}$ & $\begin{array}{l}65.10 \\
(0.00-69.95)\end{array}$ & 3 & 0.1655 \\
\hline
\end{tabular}

*P-value $<0.05,{ }^{* *}$ Not enough samples to test for VA improvement

ETDRS Early Treatment Diabetic Retinopathy Study; IQR Interquartile range; $n$ Number of patients; VA Visual Acuity

Table 3 Diagnosis of retinal diseases in the study eye

\begin{tabular}{|c|c|c|c|c|c|c|}
\hline & \multicolumn{3}{|l|}{ IVB } & \multicolumn{3}{|l|}{ IVR } \\
\hline & \multirow{2}{*}{$\begin{array}{l}\text { Number of } \\
\text { diagnosed } \\
\text { patients }\end{array}$} & \multicolumn{2}{|c|}{ Number of VA improved patients } & \multirow{2}{*}{$\begin{array}{l}\text { Number of } \\
\text { diagnosed } \\
\text { patients }\end{array}$} & \multicolumn{2}{|c|}{ Number of VA improved patients } \\
\hline & & $n$ & $\%$ & & $\mathrm{n}$ & $\%$ \\
\hline \multicolumn{7}{|l|}{ The PRN pattern } \\
\hline nAMD and PCV & 228 & 81 & 36 & 25 & 8 & 32 \\
\hline DME & 464 & 145 & 31 & 10 & 3 & 30 \\
\hline RVO & 241 & 137 & 57 & 26 & 12 & 46 \\
\hline PDR & 389 & 117 & 30 & 12 & 4 & 33 \\
\hline Others $^{*}$ & 220 & 55 & 25 & 14 & 5 & 36 \\
\hline total & 1542 & 535 & 35 & 87 & 32 & 37 \\
\hline \multicolumn{7}{|l|}{ The 3Inj pattern } \\
\hline nAMD and PCV & 57 & 26 & 46 & 12 & 4 & 33 \\
\hline DME & 52 & 24 & 46 & 1 & 0 & 0 \\
\hline RVO & 52 & 33 & 63 & 4 & 1 & 25 \\
\hline PDR & 15 & 5 & 33 & 1 & 1 & 100 \\
\hline Others $^{*}$ & 25 & 11 & 44 & 7 & 2 & 29 \\
\hline total & 201 & 99 & 49 & 25 & 8 & 32 \\
\hline
\end{tabular}

*Other disorders such as vitreous haemorrhage, subretinal haemorrhage, and subretinal fluid $D M E$ Diabetic macular edema; $n A M D$ Neovascular age-related macular degeneration; $n$, Number of patients; PCV Polypoidal choroidal vasculopathy; $R V O$ Retinal vein occlusion; PDR, Proliferative diabetic retinopathy 


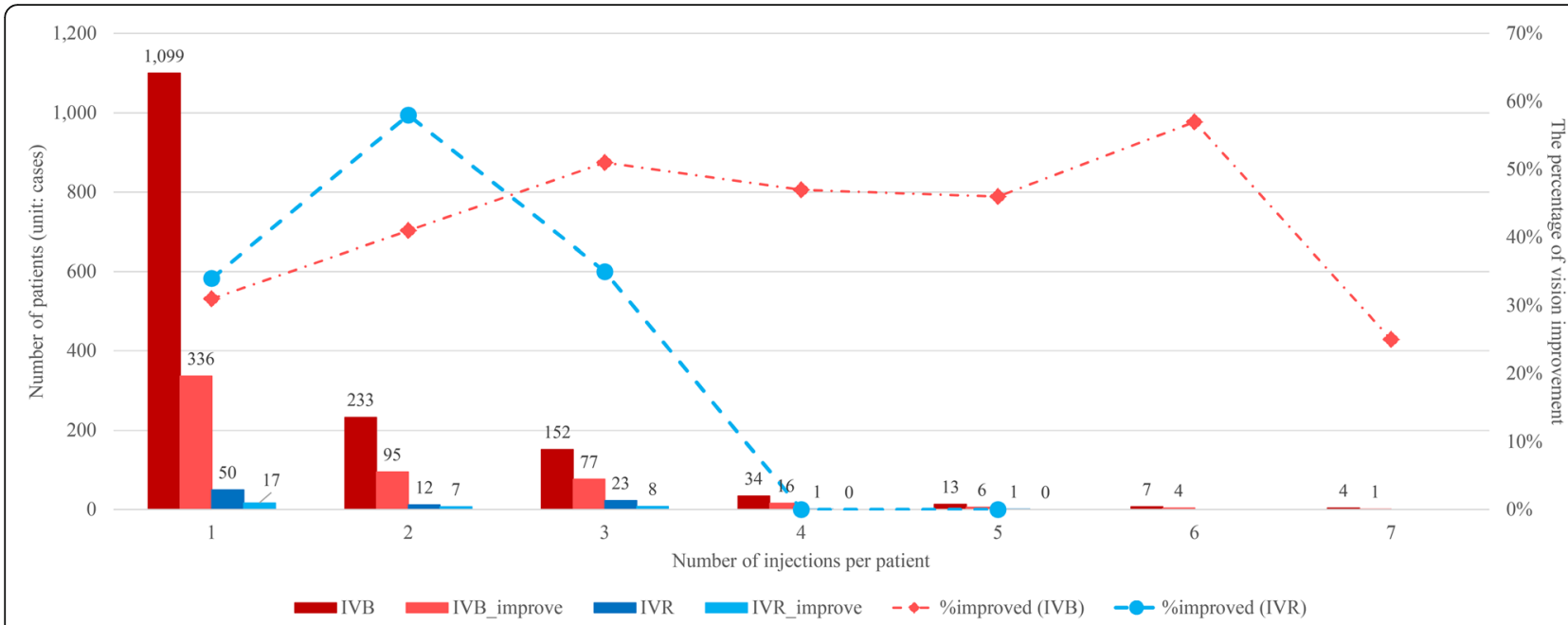

Fig. 2 Total injections per patient and percentage of vision improvement. The bar chart represents the number of patients (left $y$-axis) relative to the number of injections per patient (x-axis). The percentages of vision improvement (right $y$-axis) relative to each number of injections are indicated as line graphs

was found that age, non - DM without other comorbidities, and baseline VA score were found to be associated with VA improvement.

Multivariable models using propensity score weighting showed that there was a statistically significant difference in patients below 60 years of age for the PRN group, which increased the odds of improving vision by approximately three times compared to those over 60 years of age (odds ratio (OR) 2.92, 95\% confidence interval $(\mathrm{CI})=1.4-6.07, P$-value $=0.004$ in patients $<50$ years of age, and OR $3.25,95 \% \mathrm{CI}=1.86-$ 5.67, $P$-value $=0.000$ in patients between 50 and 60 years of age). Furthermore, patients diagnosed with RVO were significantly associated with vision improvement of approximately three times higher than those of other diseases $(95 \% \mathrm{CI}=1.20-6.34, P$-value $=$ 0.0170 ), and the odds of vision improvement per injection increased by $43 \%(95 \% \mathrm{CI}=14-78 \%, P$-value $=$ 0.0020). It was also found that patients who had lower vision at baseline were more likely to have improved VA than individuals with better vision at baseline $(\mathrm{OR} 1.08,95 \% \mathrm{CI}=1.04-1.13, \quad P$-value $=0.000)$. However, there was no statistically significant difference between the IVB and IVR patients, sex or comorbidities. In the 3Inj pattern, patients less than 50 years of age, those between 50 and 60 years of age, and baseline VA were statistically significant predictors ( $P$-value $=0.000,0.006$, and 0.009 , respectively). Additionally, it was found that having DM without other comorbidities was also a statistically significant predictor of low response for vision improvement compared to DM with other comorbidities (OR 0.16, $95 \% \mathrm{CI}=0.03-0.76, P$-value $=0.021$.

\section{Discussion}

To the best of our knowledge, this study demonstrated the first large cohort, prospective, observational IVB research for macular diseases using real-life outcome data from routine clinical practice in the Thai context. These findings showed that the proportion of visual response was not statistically different between the two drugs in both the PRN and 3Inj groups. It was also found that IVB was effective even in those with poor VA and was consistent with existing studies. For example, in nAMD treatments, patients who were treated with IVR recorded VA improvements equal to or greater than 15 ETDRS letters at a probability of approximately $33-41 \%[10,11,24$, $25,29]$. In addition, results from the meta-analysis and network meta-analysis studies in AMD and DME treatments showed no significant difference between IVR and IVB [9, 12, 13, 30].

The results of this study also highlighted that in daily routine services, ophthalmologists used anti-VEGF drugs not only for nAMD and DME but also for other retinal diseases as well. In addition, most of the data revealed that the follow-up intervals were more than 35 days and that VA measurement methods used in subsequent visits were not the same as the baseline, e.g. the pinhole method was used during the first visit but another visit used a different method. As a result, this reduced the number of patients who were eligible for evaluating drug effectiveness to only 226 patients from the 3Inj group. To increase the number of samples for future studies, VA should be measured using the same method as the baseline within 35 days of each visit during the 6-month follow-up period. 


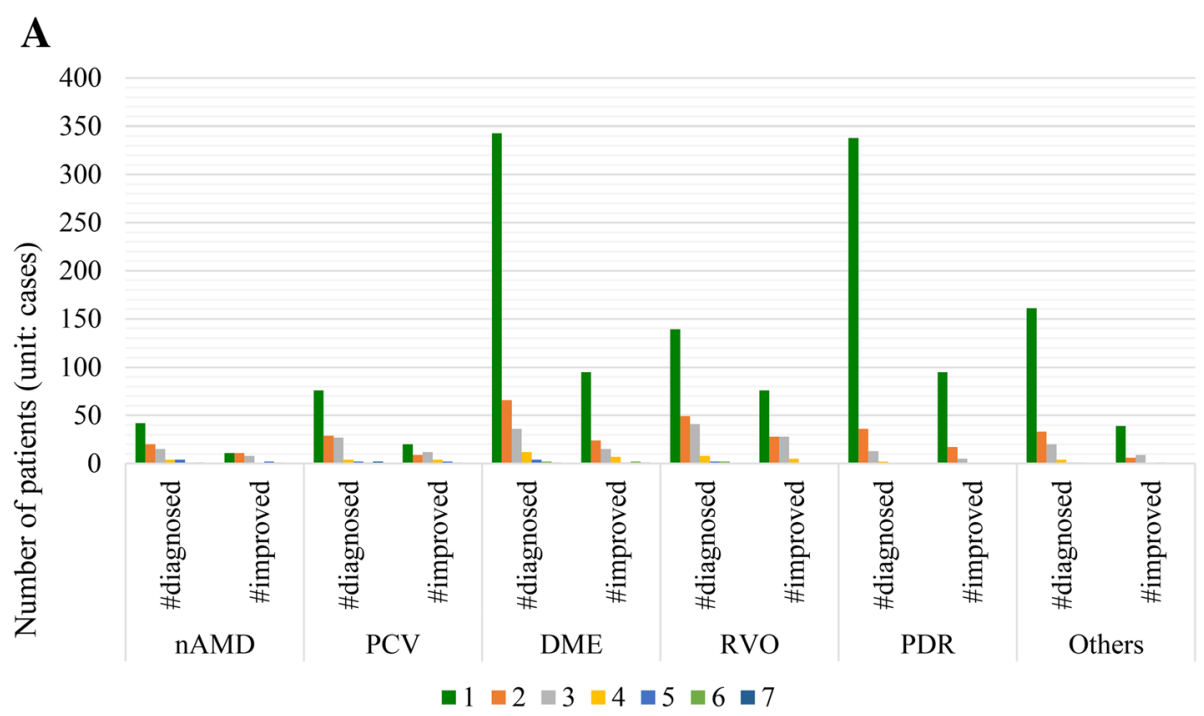

(The total number of intravitreal injections per patient)

B

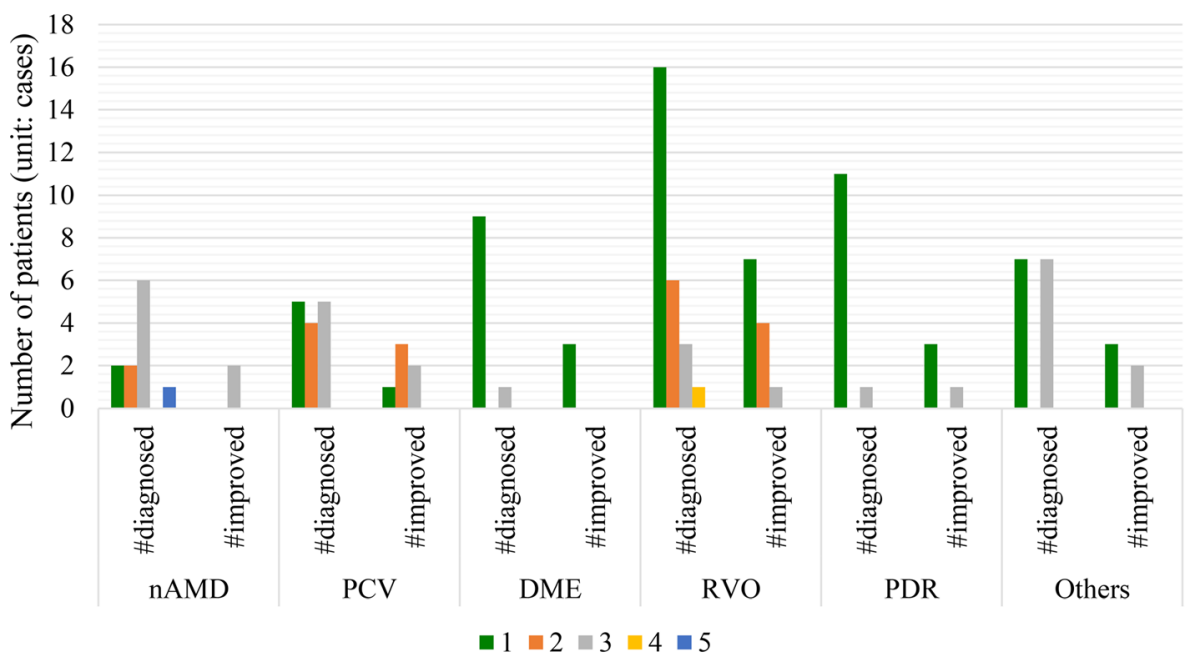

(The total number of intravitreal injections per patient)

Fig. 3 Number of patients who recorded improved VA scores for each eye disease. a Patients who received IVB. b Patients who received IVR. The numbers 1 to 7 and 1 to 5 represent the total number of IVB and IVR injections per patient for each eye disease

Furthermore, since this was an observational study, eligible patients were diagnosed and treated by their own ophthalmologists; as such, decisions about drug prescriptions, switching treatments or stoppage of treatment were made by their own ophthalmologists. Consequently, the results showed that some demographic data at the baseline did not match the findings in some RCT studies. First, median patient age was lower than previous RCT studies (approximately 70 years and older for previous studies) [11, 29, 31, 32]. However, this study's findings were consistent with research on AMD prevalence in Thailand [8], epidemiology of AMD among the Thai elderly population [33], and anti-VEGF drugs and its complications in Thailand [34]; these papers reported that the average age of their respective samples was approximately 60 years old. The reason for this may be that the median age of the patients in this study was lower as it included DME patients - who may have developed the disease at a younger age compared to nAMD patients or other retinal diseases but may also have a better prognosis as they received treatments earlier. Second, this study utilized the range of severity from NPL (unable to read the Snellen/ETDRS chart) until nearly normal VA for BCVA at baseline. However, the RCTs only included patients with BCVA from 20/25 to 20/320 [24, 29, 31, 32, 35-38]; this may reflect differences in the clinical setting, daily routine, and protocol of the controlled clinical trials. Therefore, median BCVA at baseline of the 
Table 4 Multivariable analysis of vision improvement for the PRN pattern and three-injections pattern

\begin{tabular}{|c|c|c|c|c|c|c|c|c|}
\hline \multirow[t]{2}{*}{ Variables } & \multicolumn{4}{|l|}{ PRN pattern } & \multicolumn{4}{|c|}{ Three-injections pattern } \\
\hline & $\begin{array}{l}\text { Crude OR } \\
(95 \% \mathrm{Cl})\end{array}$ & P-value & $\begin{array}{l}\text { Adjusted OR } \\
(95 \% \mathrm{Cl})\end{array}$ & P-value & $\begin{array}{l}\text { Crude OR } \\
(95 \% \mathrm{Cl})\end{array}$ & P-value & $\begin{array}{l}\text { Adjusted OR } \\
(95 \% \mathrm{Cl})\end{array}$ & P-value \\
\hline \multicolumn{9}{|l|}{ Age } \\
\hline$>60$ years & 1.0 (reference) & & 1.0 (reference) & & 1.0 (reference) & & 1.0 (reference) & \\
\hline 50 to 60 years & $1.18(0.92-1.50)$ & 0.189 & $3.25(1.86-5.67)$ & $0.000^{*}$ & $1.87(1.00-3.51)$ & 0.051 & $3.99(1.48-10.76)$ & $0.006^{*}$ \\
\hline$<50$ years & $1.23(0.95-1.58)$ & 0.113 & $2.92(1.4-6.07)$ & $0.004^{*}$ & $2.24(1.10-4.56)$ & $0.027^{*}$ & $18.38(4.61-73.36)$ & $0.000^{*}$ \\
\hline \multicolumn{9}{|l|}{ Sex } \\
\hline Male & 1.0 (reference) & & 1.0 (reference) & & 1.0 (reference) & & 1.0 (reference) & \\
\hline Female & $1.03(0.84-1.26)$ & 0.788 & $0.8(0.47-1.39)$ & 0.434 & $1.34(0.80-2.27)$ & 0.271 & $1.20(0.53-2.73)$ & 0.668 \\
\hline \multicolumn{9}{|l|}{ Drug } \\
\hline IVB & 1.0 (reference) & & 1.0 (reference) & & 1.0 (reference) & & 1.0 (reference) & \\
\hline IVR & $1.20(0.68-2.12)$ & 0.691 & $1.18(0.68-2.05)$ & 0.561 & $0.48(0.20-1.17)$ & 0.109 & $0.86(0.35-2.14)$ & 0.753 \\
\hline \multicolumn{9}{|l|}{ Co-morbidity } \\
\hline DM with other comorbidities & 1.0 (reference) & & 1.0 (reference) & & 1.0 (reference) & & 1.0 (reference) & \\
\hline DM without other comorbidities & $1.27(0.90-1.80)$ & 0.179 & $1.02(0.42-2.51)$ & 0.961 & $0.41(0.11-1.61)$ & 0.202 & $0.16(0.03-0.76)$ & $0.021^{*}$ \\
\hline non-DM with other comorbidities & $1.52(1.15-2.01)$ & $0.003^{*}$ & $0.91(0.39-2.12)$ & 0.819 & $1.31(0.70-2.43)$ & 0.400 & $0.83(0.17-4.11)$ & 0.817 \\
\hline non-DM without other comorbidities & $1.55(1.16-20.7)$ & $0.003^{*}$ & $1.52(0.63-3.65)$ & 0.349 & $2.14(1.06-4.32)$ & $0.034^{*}$ & $0.70(0.15-3.24)$ & 0.645 \\
\hline \multicolumn{9}{|l|}{ Diagnosis } \\
\hline Other diseases & 1.0 (reference) & & 1.0 (reference) & & 1.0 (reference) & & 1.0 (reference) & \\
\hline nAMD and PCV & $1.57(1.06-2.32)$ & $0.023^{*}$ & $1.66(0.73-3.78)$ & 0.226 & $1.12(0.48-2.63)$ & 0.787 & $2.36(0.52-10.7)$ & 0.266 \\
\hline DME & $1.32(0.93-1.87)$ & 0.126 & $1.39(0.49-3.97)$ & 0.535 & $1.21(0.50-2.94)$ & 0.675 & $0.88(0.15-5.13)$ & 0.883 \\
\hline RVO & $3.66(2.50-5.36)$ & $0.000^{*}$ & $2.76(1.20-6.34)$ & $0.017^{*}$ & $2.26(0.93-5.48)$ & 0.072 & $2.39(0.66-8.62)$ & 0.182 \\
\hline PDR & $1.25(0.87-1.80)$ & 0.223 & $0.85(0.30-2.41)$ & 0.756 & $0.88(0.26-3.01)$ & 0.835 & $0.42(0.04-4.09)$ & 0.454 \\
\hline Baseline VA ${ }^{a}$ & $1.05(1.04-1.07)$ & $0.000^{*}$ & $1.08(1.04-1.13)$ & $0.000^{*}$ & $1.08(1.04-1.13)$ & $0.001^{*}$ & $1.10(1.02-1.18)$ & $0.009^{*}$ \\
\hline Number of drug injections ${ }^{a}$ & $1.27(1.06-1.54)$ & $0.012^{*}$ & $1.43(1.14-1.78)$ & $0.002^{*}$ & - & - & - & - \\
\hline
\end{tabular}

${ }^{\mathrm{a} C o n t i n u o u s ~ v a r i a b l e}$

*P-value $<0.05$

OR Odds Ratio, 95\% CI 95\% confidence interval, IVB intravitreal bevacizumab, IVR intravitreal ranibizumab, DM diabetes mellitus, nAMD Neovascular age-related macular degeneration, PCV polypoidal choroidal vasculopathy, DME Diabetic macular edema, RVO Retinal vein occlusion, PDR Proliferative diabetic retinopathy, VA Visual acuity

patients in this study may be better than some existing RCTs or worse than other studies.

In addition, VA measurement in the RCTs typically used ETDRS charts because it is the gold standard and is considerably superior to Snellen chart $[39,40]$. However, this study found that several study sites performed routine ocular examinations using the Snellen chart since it was quick and simple to measure [39]. Moreover, the findings from Kalpana S. et al. [41] revealed that the Snellen and ETDRS charts may be used interchangeably for daily routine services or for RCTs. Regardless, this study used the equation proposed by Gregori et al. [26] to convert VA measured via the Snellen chart into approximate ETDRS letter scores.

When considering the number of injections, although the results showed that the proportion of VA response increased with the number of injections given - especially in the PRN pattern - it was seen that patients received a median of one injection for treatment during the 6-month follow-up period. This study's results were similar to those from other non-interventional studies, which reported that the number of anti-VEGF injections in real-life conditions was considerably lower than in the RCTs [31, 42-45]. This could be due to other possible potential factors that were not accounted for in this study such as frequency of follow-up visits; prolonged duration of eye symptoms; not realizing the importance of treatment after receiving a good baseline VA; declining motivation to receive treatment after three consecutive doses; poor access to services and hospital facilities; and non-affordable travel expenses.

The multivariable model using propensity score weighting showed that age of less than 60 years and number of drug injections were found to be positive predictive factors of vision improvement; this is consistent with results from interventional and non-interventional 
studies [31, 32, 46]. In addition, many research papers, including review articles, indicated that higher BCVA scores at baseline were associated with less VA gain from baseline values [47-52]. A retrospective study that reviewed medical records also found that VA at baseline was the most significant predictor of VA outcomes in nAMD patients who received IVB for 6 months [53-56]. Patients diagnosed with RVO were a statistically significant predictor of response compared to other disorders, such as vitreous haemorrhage, only in the PRN group and represented the highest proportion of patients with improved VA scores. However, it was not possible to perform a multivariable logistic regression analysis for individual retinal disease - including RVO - due to the inadequate number of subjects. For the 3Inj group, DM without other comorbidities was a negative predictive factor compared to DM with other comorbidities; this may be limited by the type of study, number of samples, and other associated factors. Moreover, these favourable short-term results from the multivariable analysis suggests that further studies are needed in a larger group of patients with a longer follow-up period. For VA improvement between the IVB and IVR groups, the findings were consistent with other studies in that there was no significant difference between the two drugs [12, $13,52]$.

\section{Policy implications in the Thai context}

As mentioned in the introduction, the NLEM Sub-committee included bevacizumab into the NLEM to address the issues of anti-VEGF drug affordability and IVB treatment accessibility. However, even with the available international evidence from RCTs and observational studies, Thai policy-makers and the NLEM Sub-committee itself still required safety and effectiveness information to make the most informed decisions about this inclusion. For this reason, the NLEM Sub-committee requested for the development of a safety and effectiveness monitoring system and research on real-life practices. This contrasts with the more typical process used in other countries where trials are conducted to determine evidence on safety and efficacy evidence first prior to policy implementation. Therefore, the participants included in this study would be different compared to high-income countries, where most previous and similar studies were conducted.

Another factor which was taken into consideration was the Thai health insurance infrastructure. While there are three major public health insurance schemes in Thailand comprising the UCS, SSS, and CSMBS, only government officers under the CSMBS can reimburse IVR. In the past, retina specialists previously considered prescribing IVB first for intravitreal anti-VEGF therapies as it was already included in the NLEM. The reason for this was that cost was an important factor for prescribing drug since patients had to pay IVR costs out-of-pocket, and a single injection of IVR was more expensive than a single dose of IVB (1362 USD per injection for IVR versus 544 USD/vial for IVB - equivalent to 18.16 USD per injection) [57-59]. However, since the inclusion of bevacizumab into the NLEM for nAMD and DME in 2012, all Thai citizens now have extensive access to IVB free-of-charge and are able to experience similar VA improvement outcomes compared to IVR.

In addition, while this study was ongoing, the World Health Organization added bevacizumab to its Essential Medicine List for ophthalmic indication [60]. Hence, this action supports the use of IVB and its ability to create equitable access of essential medicines for macular disease patients in Thailand. Data from the national database also illustrated an increasing trend in the number of new patients who received IVB, rising from 2694 cases in fiscal year 2013 to 3908, 4535, and 6979 in fiscal years 2014, 2015, and 2016, respectively [61].

\section{Limitations of study}

The results of this study should be interpreted with caution. First, the main study focused on generating evidence for IVB to inform policy-makers and the NLEM Sub-committee. Thus, this study primarily aimed to assess the effectiveness of IVB in real-life practice. Second, only a small number of patients received IVR. This imbalance in the number of patients and patient characteristics between the drug groups due to the lack of randomization may have led to bias and confounding but was addressed by using the propensity score method to minimise possible biases. Third, the follow-up period was only 6 months, and this may not have captured the long-term effect, efficacy or effectiveness of both drugs on visual outcomes. Although there are several RCT studies which utilized a follow-up period of 12-month, the results of studies conducted in LMICs are likely to be out of date as evidence generation in those real-world settings has been scarce. Therefore, capturing the long-term effect, efficacy, and effectiveness of both drugs is still important for these settings as they have different contexts from developed or high-income countries. Together with suggestions from Thai retina specialists, it is accepted that the follow-up period of 6 months is sufficient for real-world practice to examine the short-term effectiveness of anti-VEGF drugs in Thailand. However, the long-term outcomes such as 1 -year monitoring and evaluation are still needed to confirm the effectiveness of this intervention for further feedback to stakeholders. Fourth, multiple VA measurement methods were used in real-world practice, including ETDRS and Snellen charts as well as semi-quantitative methods such as CF and HM; this contributed to the diversity in VA reporting among our study sites. Therefore, 
a formula [26] was used to convert all VA scores into the same unit for measuring outcomes. Lastly, unlike other studies, CMT measurement was not included in the analysis as it is not covered by the health schemes and is considered optional. When reviewing the medical records during the data gathering process, there were many cases of missing CMT data, making any further analysis unfeasible. Therefore, further studies should employ a matching case approach in the observational study to avoid selection bias and conduct a follow-up regarding the long-term consequences of IVB treatment. This should be conducted together with designing further policy implications for optimising treatment regimens and indications in the pharmaceutical benefit package.

\section{Conclusions}

This study included patients with more varied diseases and demographics than in previous RCTs and used various treatment patterns which can be generalized to other real-life settings with macular patients. The results also provided evidence that under real-world conditions, IVB is just as effective as IVR in improving VA. Thus, IVB can be considered as an alternative drug for patients who need treatment but are unable to afford IVR.

The findings of this study may reflect real-world outcomes and generate evidence to inform policy for allocating resources, refining the NLEM, and providing information to ophthalmologists and patients to improve confidence in prescribing and using IVB. Additionally, the results may also benefit future policy implementation in the long-run for Thailand or other developing countries with similar interests by enhancing the retinal treatment system, safety monitoring systems, and individual data management systems for retinal diseases.

\section{Abbreviations}

3Inj: Three-injections; BCVA: Best-corrected visual acuity; CATT: The Comparison of Age-related macular degeneration Treatments Trials; CF: Counting fingers; Cl: Confidence interval; CKD: Chronic kidney disease; CMT: Central macular thickness; CSMBS: Civil Servant Medical Benefit Scheme; DLP: Dyslipidaemia; DM: Diabetes mellitus; DME: Diabetic macular edema; ETDRS: Early Treatment Diabetic Retinopathy Study; HITAP: Health Intervention and Technology Assessment Program; HM: Hand movements; HTN: Hypertension; IHD: Ischaemic heart disease; IQR: Interquartile ranges; IVAN: Inhibition of VEGF in Age-related choroidal Neovascularisation; IVB: Intravitreal bevacizumab; IVR: Intravitreal ranibizumab; nAMD: Neovascular age-related macular degeneration; NLEM: National list of essential medicines; NPL: No light perception; OR: Odds ratio; PCV: Polypoidal choroidal vasculopathy; PDR: Proliferative diabetic retinopathy; PL: Perception of light; PRN: Pro re nata; RCTs: Randomised control trials; RVO: Retinal vein occlusion; SSS: Social Security Scheme; UCS: Universal Coverage Scheme; VA: Visual acuity; VEGF: Vscular endothelial growth factor

\section{Acknowledgements}

The authors would like to express deep gratitude and sincere appreciation to the Thai Retina Society, the Royal College of Ophthalmologists of Thailand, ophthalmologists, and support staff from all study sites for their valuable comments and support.

\section{Funding}

This study was funded by the Health Systems Research Institute, Thailand. The Health Intervention and Technology Assessment Program is funded by the Thailand Research Fund (TRF) under the grant for Senior Research Scholar on Health Technology Assessment (RTA 5980011). Contribution of SS and UC to the study have been funded through the Royal Golden Jubilee Ph.D. Program (Grant No. PHD/0180/2554) provided by the TRF and Mahidol University. The findings, interpretations, and conclusions expressed in this paper do not necessarily reflect the views of the funding agencies. The funding body had no influence on the design, collection, analysis or interpretation of the data, or in writing the manuscript.

\section{Availability of data and materials}

The data that support the findings of this study are available upon request from the corresponding author [LI]. The data are not publicly available due to containing information that could compromise the privacy of research participants. Data are available from the authors upon reasonable request and with permission of the Institute for the Development of Human Research Protections, Ministry of Public Health, Thailand.

\section{Authors' contributions}

YT TR1 PL SS and UC designed the study. SK and SS performed data collection. SK, LI and SS conducted data management, statistical data analysis and data interpretation. TR1, PR, WT, JC, ST, PH, KK, TR2, WW supervised in the data collection, interpretation of data and provided critical feedback to this work in views of ophthalmologists and all authors suggested the policy recommendations. SK and $\mathrm{LI}$ drafted and revised the manuscript. All authors read and approved the final version of the manuscript.

\section{Ethics approval and consent to participate}

This research was approved by the Institute for the Development of Human Research Protections, Ministry of Public Health, Thailand (IHRP.32/2012), the Thai Clinical Trials Registry (TCTR20141002001), and the institutional review board of each hospital. All patients were enrolled into the study after providing written informed consent.

\section{Consent for publication \\ Not applicable.}

\section{Competing interests}

Prut Hanutsaha has received an honorarium and travel support from Novartis to attend a scientific meeting. Wongsiri Taweebanjongsin has received an honorarium from Novartis, a travel support to meeting from TRB Chemedica, and payment for lectures from Novartis and Bayer. Other authors declare that they have no competing interests which are directly relevant to the content of this study.

\section{Publisher's Note}

Springer Nature remains neutral with regard to jurisdictional claims in published maps and institutional affiliations.
Author details
${ }^{1}$ Health Intervention and Technology Assessment Program (HITAP), Ministry of Public Health, Nonthaburi, Thailand. '2Department of Statistics, Faculty of Science, Kasetsart University, Bangkok, Thailand. ${ }^{3}$ Social and Administrative Pharmacy Excellence Research (SAPER) Unit, Department of Pharmacy, Faculty of Pharmacy, Mahidol University, Bangkok, Thailand. ${ }^{4}$ Department of Ophthalmology, Faculty of Medicine, Khon Kaen University, Khon Kaen, Thailand. ${ }^{5}$ Department of Ophthalmology, Rajavithi Hospital, Bangkok, Thailand. ${ }^{6}$ Department of Ophthalmology, Mettapracharak (Wat Rai Khing) Hospital, Nakornprathom, Thailand. 'Department of Ophthalmology, Faculty of Medicine, Chiang Mai University, Chiang Mai, Thailand. ${ }^{8}$ Department of Ophthalmology, Faculty of Medicine, Siriraj Hospital, Mahidol University, Bangkok, Thailand. 'Department of Ophthalmology, Faculty of Medicine, Ramathibodi Hospital, Mahidol University, Bangkok, Thailand. ${ }^{10}$ Vitreo-Retina Research Unit, Department of Ophthalmology, Faculty of Medicine, Chulalongkorn University, Bangkok, Thailand. ${ }^{11}$ Department of Ophthalmology, Phramongkutklao Hospital, Phramongkutklao College of Medicine, Bangkok, Thailand. 
Received: 27 March 2018 Accepted: 6 March 2019 Published online: 29 March 2019

\section{References}

1. Rogers S, McIntosh RL, Cheung N, Lim L, Wang JJ, Mitchell P, et al. The prevalence of retinal vein occlusion: pooled data from population studies from the United States, Europe, Asia, and Australia. Ophthalmology. 2010; 117(2):313-9.

2. Yau JW, Rogers SL, Kawasaki R, Lamoureux EL, Kowalski JW, Bek T, et al. Global prevalence and major risk factors of diabetic retinopathy. Diabetes Care. 2012:35(3):556-64.

3. Lanzetta P, Loewenstein A. Fundamental principles of an anti-VEGF treatment regimen: optimal application of intravitreal anti-vascular endothelial growth factor therapy of macular diseases. Graefes Arch Clin Exp Ophthalmol. 2017:255(7):1259-73.

4. Ishikawa M, Jin D, Sawada Y, Abe S, Yoshitomi T. Future therapies of wet age-related macular degeneration. J Ophthalmol. 2015;2015:10.

5. Wong WL, Su X, Li X, Cheung CM, Klein R, Cheng CY, et al. Global prevalence of age-related macular degeneration and disease burden projection for 2020 and 2040: a systematic review and meta-analysis. Lancet Glob Health. 2014;2(2):e106-16.

6. Ding J, Wong TY. Current epidemiology of diabetic retinopathy and diabetic macular edema. Current Diabetes Reports. 2012;12(4):346-54.

7. Ting DSW, Cheung GCM, Wong TY. Diabetic retinopathy: global prevalence, major risk factors, screening practices and public health challenges: a review. Clin Exp Ophthalmol. 2016:44(4):260-77.

8. Jenchitr W, Ruamviboonsuk P, Sanmee A, Pokawattana N. Prevalence of age-related macular degeneration in Thailand. Ophthalmic Epidemiol. 2011; 18(1):48-52.

9. Anothaisintawee T, Leelahavarong P, Ratanapakorn T, Teerawattananon Y. The use of comparative effectiveness research to inform policy decisions on the inclusion of bevacizumab for the treatment of macular diseases in Thailand's pharmaceutical benefit package. ClinicoEconomics and Outcomes Research. 2012;4:361-74

10. Brown DM, Kaiser PK, Michels M, Soubrane G, Heier JS, Kim RY, et al. Ranibizumab versus Verteporfin for Neovascular age-related macular degeneration. N Engl J Med. 2006:355(14):1432-44.

11. Rosenfeld PJ, Brown DM, Heier JS, Boyer DS, Kaiser PK, Chung CY, et al. Ranibizumab for neovascular age-related macular degeneration. N Engl J Med. 2006;355(14):1419-31.

12. Solomon SD, Lindsley K, Vedula SS, Krzystolik MG, Hawkins BS. Anti-vascular endothelial growth factor for neovascular age-related macular degeneration. Cochrane Database Syst. Rev. 2014;8.

13. Virgili G, Parravano M, Menchini F, Evans JR. Anti-vascular endothelial growth factor for diabetic macular oedema. Cochrane Database Syst. Rev. 2014:(10):Cd007419.

14. Ford JA, Elders A, Shyangdan D, Royle P, Waugh N. The relative clinical effectiveness of ranibizumab and bevacizumab in diabetic macular oedema: an indirect comparison in a systematic review. BMJ. 2012;345.

15. Schmucker C, Ehlken C, Agostini HT, Antes G, Ruecker G, Lelgemann M, et al. A safety review and meta-analyses of bevacizumab and Ranibizumab: offlabel versus Goldstandard. PLoS One. 2012;7(8):e42701.

16. van der Reis MI, La Heij EC, De Jong-Hesse Y, Ringens PJ, Hendrikse F, Schouten JS. A systematic review of the adverse events of intravitreal antivascular endothelial growth factor injections. Retina. 2011:31(8):1449-69.

17. Tangcharoensathien $V$, Limwattananon S, Patcharanarumol W, Thammatacharee J, Jongudomsuk P, Sirilak S. Achieving universal health coverage goals in Thailand: the vital role of strategic purchasing. Health Policy Plan. 2015;30(9):1152-61.

18. Paek SC, Meemon N, Wan TTH. Thailand's universal coverage scheme and its impact on health-seeking behavior. SpringerPlus. 2016;5(1):1952.

19. Patcharanarumol W, Panichkriangkrai W, Sommanuttaweechai A, Hanson K, Wanwong Y, Tangcharoensathien V. Strategic purchasing and health system efficiency: a comparison of two financing schemes in Thailand. PLoS One. 2018;13(4):e0195179

20. Sangroongruangsri S, Chaikledkaew U, Kumluang S, Wu O, Geue C, Ratanapakorn T, et al. Real-world safety of intravitreal bevacizumab and Ranibizumab treatments for retinal diseases in Thailand: a prospective observational study. Clin. Drug Investig. 2018;38(9):853-65.

21. The Royal College of Ophthalmology of Thailand. Summary benchmarks for preferred practice pattern guidelines: Thai translation (in Thai). San
Francisco: American Academy of Ophthalmology; 2013. https://www.aao. org/Assets/480a5654-b6a2-449e-8e54-aac93498df19/

635116445677530000/thai-summary-benchmarks-2013-pdf. Accessed 17 Aug 2016.

22. Working Group for the outline criteria use and monitoring on E2 category under the Sub-committee for development of the NLEM. The outline criteria use and monitoring on E2 category: bevacizumab for nAMD and DME (in Thai). Nonthaburi, Thailand: Ministry of public health, Thailand; 2015. http://www.fda.moph.go.th/sites/drug/Shared\%20Documents/ National-Drug-Policy/04/01/17\%20Bevacizumab\%20AMD_DME\%20Guide_ 2559.pdf. Accessed 18 Sept 2017

23. Bureau of Medicines Medical Supplies and Vaccines Management. Preauthorization form: Bevacizumab for Wet form of subfoveal, juxtafoveal choroidal neovascularization (CNV) due-to aged related macular degeneration and Diabetic Macular Edema (DME). 20152 Oct 2018. http://drugfund.nhso.go.th/drugfund/webfiles/images/ 26112015032819-18BevacizumabAMD_DMEGuide_2015.pdf. Accessed 2 Oct 2018.

24. The CATT Research Group. Ranibizumab and bevacizumab for Neovascular age-related macular degeneration. N Engl J Med. 2011;364(20):1897-908.

25. Chakravarthy U, Harding SP, Rogers CA, Downes SM, Lotery AJ, Culliford LA, et al. Alternative treatments to inhibit VEGF in age-related choroidal neovascularisation: 2-year findings of the IVAN randomised controlled trial. Lancet. 2013;382(9900):1258-67.

26. Gregori NZ, Feuer W, Rosenfeld PJ. Novel method for analyzing snellen visual acuity measurements. Retina. 2010;30(7):1046-50.

27. Austin PC. An introduction to propensity score methods for reducing the effects of confounding in observational studies. Multivar Behav Res. 2011; 46(3):399-424

28. Cepeda MS, Boston R, Farrar JT, Strom BL. Comparison of logistic regression versus propensity score when the number of events is low and there are multiple confounders. Am J Epidemiol. 2003;158(3):280-7.

29. Martin DF, Maguire MG, Fine SL, G-S Y, Jaffe GJ, Grunwald JE, et al. Ranibizumab and bevacizumab for treatment of Neovascular age-related macular degeneration: two-year results. Ophthalmology. 2012;119(7):1388-98

30. Agarwal A, Aggarwal K, Gupta V. Management of neovascular age-related macular degeneration: a review on landmark randomized controlled trials. Middle East Afr J Ophthalmol. 2016;23(1):27-37.

31. Writing Committee for the UK Age-Related Macular Degeneration EMR Users Group. The neovascular age-related macular degeneration database: multicenter study of 92976 ranibizumab injections: report 1: visual acuity. Ophthalmology. 2014;121(5):1092-101.

32. Ying GS, Maguire MG, Daniel E, Ferris FL, Jaffe GJ, Grunwald JE, et al. Association of Baseline Characteristics and Early Vision Response with 2-year vision outcomes in the comparison of AMD treatments trials (CATT). Ophthalmology. 2015;122(12):2523-31 e1

33. Khotcharrat R, Patikulsila D, Hanutsaha P, Khiaocham U, Ratanapakorn T, Sutheerawatananonda $M$, et al. Epidemiology of age-related macular degeneration among the elderly population in Thailand. J Med Assoc Thail. 2015;98(8):790-7.

34. Kunavisarut P, Saenpen N, Ittipunkul N, Patikulsila D, Choovuthayakorn J, Watanachai $\mathrm{N}$, et al. The use of intravitreal anti-vascular endothelial growth factor injection and its complications in Chiang Mai University Hospital. J Med Assoc Thail. 2013;96(11):1483-90.

35. Berg K, Pedersen TR, Sandvik L, Bragadóttir R. Comparison of Ranibizumab and bevacizumab for Neovascular age-related macular degeneration according to LUCAS treat-and-extend protocol. Ophthalmology. 2015;122(1):146-52.

36. Cai S, Bressler NM. Aflibercept, bevacizumab or ranibizumab for diabetic macular oedema: recent clinically relevant findings from DRCR.net protocol T. Curr Opin Ophthalmol. 2017;28(6):636-43.

37. Holekamp NM, Campbell J, Almony A, Ingraham H, Marks S, Chandwani H, et al. Vision outcomes following anti-vascular endothelial growth factor treatment of diabetic macular edema in clinical practice. Am J Ophthalmol. 2018;191:83-91.

38. Kodjikian L, Souied EH, Mimoun G, Mauget-Faÿsse M, Behar-Cohen F, Decullier E, et al. Ranibizumab versus bevacizumab for Neovascular agerelated macular degeneration: results from the GEFAL noninferiority randomized trial. Ophthalmology. 2013;120(11):2300-9.

39. Kaiser PK. Prospective evaluation of visual acuity assessment: a comparison of snellen versus ETDRS charts in clinical practice (an AOS thesis). Trans Am Ophthalmol Soc. 2009;107:311-24. 
40. Cotter SA, Chu RH, Chandler DL, Beck RW, Holmes JM, Rice ML, et al. Reliability of the electronic early treatment diabetic retinopathy study testing protocol in children 7 to $<13$ years old. Am J Ophthalmol. 2003; 136(4):655-61.

41. Kalpana S, Karthick J, Jayarajini S. Comparison of static visual acuity between Snellen and early treatment diabetic retinopathy study charts. Int. J. Educ Res. Dev. 2013;2(3):82-8.

42. Cvetkova N, Maerker D, Helbig H, Hoelldobler K. Ranibizumab (Lucentis) in neovascular age- related macular degeneration (AMD): five year follow up. Invest Ophthalmol Vis Sci. 2014;55(13):3951.

43. Lad EM, Hammill BG, Qualls LG, Wang F, Cousins SW, Curtis LH. Anti-VEGF treatment patterns for neovascular age-related macular degeneration among medicare beneficiaries. Am J. Ophthalmol. 2014;158(3):537-43.e2.

44. Wolf A, Kampik A. Efficacy of treatment with ranibizumab in patients with wet age-related macular degeneration in routine clinical care: data from the COMPASS health services research. Graefes Arch Clin Exp Ophthalmol. 2014; 252(4):647-55.

45. Souied EH, Oubraham H, Mimoun G, Cohen SY, Quere S, Derveloy A. Changes in visual acuity in patients with wet age-related macular degeneration treated with intravitreal ranibizumab in daily clinical practice: the twin study. Retina. 2015;35(9):1743-9.

46. Holz FG, Tadayoni R, Beatty S, Berger A, Cereda MG, Hykin P, et al. Key drivers of visual acuity gains in neovascular age-related macular degeneration in real life: findings from the AURA study. Br J Ophthalmol. 2016;100:1623-8

47. Tsilimbaris MK, Lopez-Galvez MI, Gallego-Pinazo R, Margaron P, Lambrou GN. Epidemiological and clinical baseline characteristics as predictive biomarkers of response to anti-VEGF treatment in patients with Neovascular AMD. J Ophthalmol. 2016;2016:4367631.

48. Boyer DS, Antoszyk AN, Awh CC, Bhisitkul RB, Shapiro H, Acharya NR. Subgroup analysis of the MARINA study of ranibizumab in neovascular agerelated macular degeneration. Ophthalmology. 2007;114(2):246-52.

49. Kaiser PK, Brown DM, Zhang K, Hudson HL, Holz FG, Shapiro H, et al. Ranibizumab for predominantly classic neovascular age-related macular degeneration: subgroup analysis of first-year ANCHOR results. Am J Ophthalmol. 2007;144(6):850-7.

50. Hariprasad SM, Morse LS, Shapiro H, Wong P, Tuomi L. Fixed monthly versus less frequent Ranibizumab dosing and predictors of visual response in exudative age-related macular degeneration. J Ophthalmol. 2012;2012:8.

51. Ying GS, Huang J, Maguire MG, Jaffe GJ, Grunwald JE, Toth C, et al. Baseline predictors for one-year visual outcomes with ranibizumab or bevacizumab for neovascular age-related macular degeneration. Ophthalmology. 2013; 120(1):122-9.

52. Wells JA, Glassman AR, Ayala AR, Jampol LM, Bressler NM, Bressler SB, et al. Aflibercept, Bevacizumab, or Ranibizumab for Diabetic Macular Edema. Ophthalmology. 2016;123(6):1351-9.

53. Fang K, Tian J, Qing X, Li S, Hou J, Li J, et al. Predictors of visual response to intravitreal bevacizumab for treatment of Neovascular age-related macular degeneration. J Ophthalmol. 2013;2013:9.

54. Singh RP, Fu EX, Smith SD, Williams DR, Kaiser PK. Predictive factors of visual and anatomical outcome after intravitreal bevacizumab treatment of neovascular age-related macular degeneration: an optical coherence tomography study. Br J Ophthalmol. 2009;93:1353-8.

55. Levy J, Shneck M, Rosen S, Klemperer I, Rand D, Weinstein O, et al. Intravitreal bevacizumab (avastin) for subfoveal neovascular age-related macular degeneration. Int Ophthalmol. 2008;29(5):349.

56. Chhablani J, Kozak IR, Mojana F, Cheng L, Morrison VL, Wang H, et al. Fundus autofluorescence not predictive of treatment response to intravitreal bevacizumab in exudative age-related macular degeneration. Retina. 2012;32(8):1465-70.

57. The Drug And Medical Supply Information Center. Reference Price database: BEVACIZUMAB VIAL 100 MG /4ML (4 ML). Nonthaburi, Thailand: Ministry of Public Health; 2017. http://dmsic.moph.go.th/dmsic/index.php?p=1\&type= $3 \& s=3 \& i d=$ drug_normal\&keyword $=b \& s h=1 \&$ sid $=$ BEVACIZUMAB\%20VIAL\%20100\%20MG\%20/4ML\%20(4\%20ML). Accessed 5 July 2017.

58. The Drug And Medical Supply Information Center. Reference Price Database: RANIBIZUMAB VIAL 10 MG /ML (0.23 ML). Nonthaburi, Thailand: Ministry of Public Health; 2017. http://dmsic.moph.go.th/dmsic/index. php? $=1 \&$ type $=3 \& s=3 \& i d=$ drug_normal\&keyword $=r \& s h=1 \&$ sid $=$
RANIBIZUMAB\%20VIAL\%2010\%20MG\%20/ML\%20(0.23\%20ML). Accessed 18 Sept 2017.

59. Rates of Exchange of Commercial Banks in Bangkok Metropolis (2002present). Bank of Thailand; 2017. http://www2.bot.or.th/statistics/ReportPage. aspx? report|D=123\&language=eng. Accessed 28 Dec 2017.

60. World Health Organization. The selection and use of essential medicines. Report of the WHO Expert Committee, 2015 (including the 19th WHO Model List of Essential Medicines and the 5th WHO Model List of Essential Medicines for Children). Geneva: World Health Organization2015 (WHO Technical Report Series, No. 994). https://apps.who.int/iris/bitstream/handle/ 10665/189763/9789241209946 eng.pdf;jsessionid=C35F0747D258F60EA88 2499660BCC8A0?sequence=1. Accessed 6 July 2017.

61. National Health Security Office. NHSO annual report 2016. National Health Security Office: Bangkok; 2017. http://www.nhso.go.th/frontend/pageabout_result.aspx. Accessed 5 July 2017.

\section{Ready to submit your research? Choose BMC and benefit from:}

- fast, convenient online submission

- thorough peer review by experienced researchers in your field

- rapid publication on acceptance

- support for research data, including large and complex data types

- gold Open Access which fosters wider collaboration and increased citations

- maximum visibility for your research: over $100 \mathrm{M}$ website views per year

At BMC, research is always in progress.

Learn more biomedcentral.com/submissions 